\title{
AUTOMATED DETECTION OF COLLAPSED BUILDINGS WITH USE OF OPTICAL AND SAR IMAGES, CASE STUDY: IZMIR EARTHQUAKE ON OCTOBER 30TH,2020
}

\author{
O. Ekmekcioglu ${ }^{1 *}$, N. Demir ${ }^{1,2,3}$ \\ ${ }^{1}$ Akdeniz University, Institute of Natural and Applied Sciences, Department of Space Sci. and Technologies, \\ 07058, Konyaalti, Antalya, Turkey - ouzekm@gmail.com, nusretdemir@akdeniz.edu.tr \\ ${ }^{2}$ Akdeniz University, Faculty of Science, Department of Space Sci. and Technologies, 07058, Konyaalti, Antalya, Turkey \\ ${ }^{3}$ Akdeniz University, Institute of Natural and Applied Sciences, Department of Remote Sensing and GIS, \\ 07058, Konyaalti, Antalya, Turkey
}

\section{Commission III/IVa}

KEY WORDS: Earthquake, Optical Satellite Image, SAR, Google Colab, ICEYE, MAXAR

\begin{abstract}
:
In this study, we have analysed the optical and SAR images both to detect the collapsed building automatically with the use of the cloud-based programming environment Google Colab Cloud environment. We have used the existing digital map of buildings which were provided by Here Maps Company, for each building feature, the histograms were generated both for optical and SAR images, the unmatched histograms on the optical image were mainly the destroyed buildings and newly established tent areas for the people who lost their homes. In the method, the most recent (before and after) optical images of the earthquake zone are taken. Some preprocessing steps were performed including principal component analysis, K-Means clustering. Then, the statistical values of area overlap with the building vectors are calculated and the threshold values are determined. SAR images are used to refine the results. he used optical satellite images are Worldview images with $30 \mathrm{~cm} \mathrm{GSD}$, and for SAR images, Sentinel $1 \mathrm{C}$ band and ICEYE X band SAR images are used. Sentinel 1 and ICEYE images are provided from ESA.
\end{abstract}

\section{INTRODUCTION}

Earthquakes, one of the biggest natural disasters; It affects the regions where it occurs to a great extent and poses a great threat to the safety of human life. Remote sensing data can remotely observe the surface of the earth and when the disaster occurs, it enables a model of the disaster to be created without going to the area where the earthquake occurred (Huyck et al., 2005). Remote sensing science is an essential to do damage analysis with both optical and SAR satellite imagery (Brunner et al., 2010). In recent years, with the rapid development of multiplatform and multi-sensor remote sensing technologies, it has become possible to obtain remote sensing data from satellite and air platforms quickly after an earthquake (Janalipour and Mohammadzadeh, 2016; Liu and Yamazaki, 2012). In particular, the information by the phase and amplitude of the SAR signal is used for various purposes such as crustal deformation analysis (Stramondo et al., 2016), classification studies (Chini et al., 2009; Pulvirenti et al., 2016), or damage mapping in post-emergency scenarios (Piscini et al., 2017; Stramondo et al., 2006).

According to different input data, there are two types of methods of obtaining damage status from remotely sensed images: methods based on pre- and post-earthquake historical images and methods based on single-date images after the earthquake. In general, major earthquakes are studied to obtain information about the general structure of major fault lines. However, besides large faults, small to medium sized earthquakes on secondary and main faults are as important as large earthquakes in terms of information content (Massonnet et al., 1993).

Dong and Shan, (2013) provide a comprehensive review on earthquake damaged building detection from various remote sensing data sources including active and passive datasets. They provide the list of methodologies which use optical data, SAR data by applying image enhancements, pre-post images analysis for the optical, and investigating the amplitude and phase differences for the SAR data. They also discuss the papers which focus on LIDAR-based approaches for the damaged buildings detection.

The recent studies those use of different types of satellite data for the damaged buildings, deep learning methodologies (Adriano et al., 2021; Ünlü and Kiriş, 2021; Yang et al., 2021) are quite popular, due to high demand of labelling data and processing cost, there are still methods which apply the conventional methods such as histogram analysis(Du et al., 2020), classification (Stepinac et al., 2021) and others such as SAR coherence analysis (ElGharbawi and Zarzoura, 2021).

As shown previous studies which are pre-post image analysis, we have tried to fuse the capabilities of high resolution optical and X-band SAR datasets with combination of existing building vector data as well.

\footnotetext{
* Corresponding Author
} 
$42 \%$ of Turkey's land has been classified as the first degree and $24 \%$ and $18 \%$ are the second and third-degree earthquake zone according to published report by Mine and Exploration Directorate of Turkey (Özmen, 2012), the country faces earthquakes frequently with many life losses and fatalities including totally collapsed buildings.

In this study, we have selected a test region where the collapsed and damaged buildings are present.

In this study, the case of Izmir Earthquake is selected, which was actually called Samos EQ internationally, but effected Izmir city much where close to Samos island. The detailed information of the aftermath from the EQ can be found in several reports which were published by the state authorities and universities (Azak, 2020; Deniz et al., 2020; Nurlu, 2020; Sozbilir et al., 2020). The EQ happened on October 30, 2020, at 14.51 local time in the Aegean Sea with Mw 6.6 according to AFAD (Disaster and Emergency Management Office of Turkey), Mw 6.9 according to Bogazici University Kandilli Observatory. The epicentre of the EQ was on the island of Samos, around the town of Avlakia (Azak, 2020).

Our methodology is based on the histogram comparison both for the optical and SAR images with integrating the existing building vector datasets. As the optical and SAR images have different types of characteristics, advantages and disadvantages compare to the other, we have developed an approach that uses different parameters for each, and the parameters are calculated automatically without any user interaction.

\section{MATERIAL AND METHOD}

\subsection{Study Area}

Izmir is the third largest city of Turkey where the fault zones are close by. Izmir is in the highest earthquake risk area according to the respective authorities of the country. The city has been faced by the earthquakes with high magnitudes in 1928 (Torbali), 1949 (Karaburun), 1992 (Seferihisar) (Kutluca, 2006) and 2020 (Samos). The detailed information regarding the geological characteristics of the city can be found in (Kutluca, 2006).

The population of Izmir is 4,394,694 as of 2020. The people live in 30 districts and 1.297 quarters. On October 30th, 2020, the island of Greek island which is close to Turkey had an earthquake with 6.9 ML, there were 119 deaths in Turkey (117 in Izmir) and Greece ( 2 in Samos), and many buildings were damaged in both countries, mainly in Izmir-Bayrakli district. We have selected an area for testing the developed approach as shown in Figure 1.

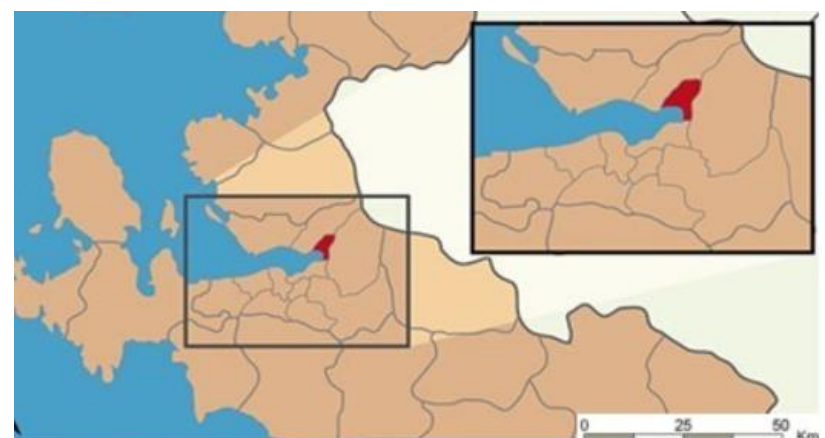

Figure 1. Red area is Bayrakli distinct where the earthquake most effected the area.
The selected area consists 1257 building where the damaged and collapsed buildings present as shown in Figure 2.

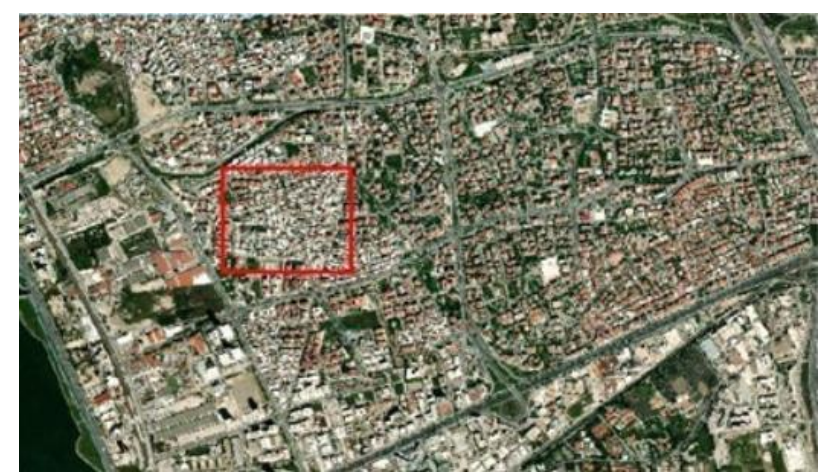

Figure 2. The investigated area is shown in red rectangle.

\subsection{Used Data}

In this study, optical and SAR satellite images, building vector data were used.

\subsubsection{Optical Satellite Image}

Optical satellite data was provided by Maxar's open data program. The sensors of Maxar program are Worldview consolation. The sensor information is not found in the given dataset metadata. The provided data are the images acquired before and after the earthquake that occurred on November 30 , 2020.

The properties of the used optical images are listed in Table 1.

\begin{tabular}{|l|l|}
\hline \multicolumn{1}{|c|}{ Property } & \multicolumn{1}{c|}{ Value } \\
\hline Before Earthquake \\
\hline Spatial Resolution & $0.40 \mathrm{~m}$ \\
\hline Radiometric Resolution & $32 \mathrm{bit}$ \\
\hline Datum/Projection & WGS84/UTM 36N \\
\hline Acquisition date After Earthquake \\
\hline \multicolumn{2}{|c|}{ April 27h, 2020 } \\
\hline Spatial Resolution & $0.40 \mathrm{~m}$ \\
\hline Radiometric Resolution & 32 bit \\
\hline Datum/Projection & WGS84/UTM 36N \\
\hline Acquisition date & April 27h, 2020 \\
\hline
\end{tabular}

Table 1. Properties of the optical satellite image.

The used optical images are found in Figure 3.
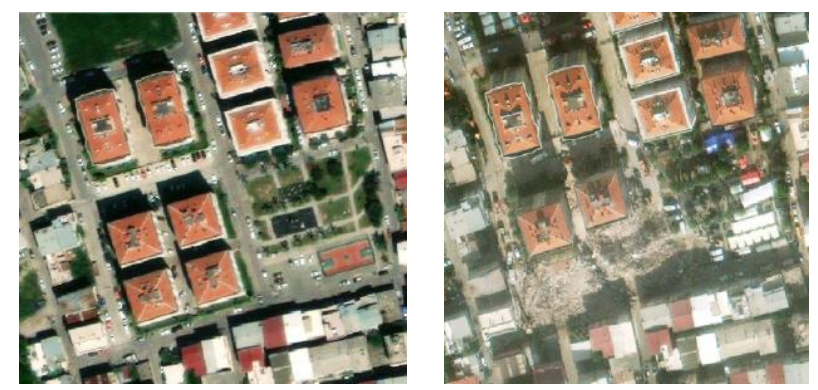

Figure 3. A sample from the optical image (left: pre-EQ, right: post-EQ).

In Figure 3, two collapsed buildings are shown. 
SAR images from pre- and post-earthquake were acquired by Finland based ICEYE sensors by the following properties listed in Table 2.

\begin{tabular}{|c|c|}
\hline Property & Value \\
\hline \multicolumn{2}{|c|}{ Before Earthquake } \\
\hline Spatial Resolution & $3 \mathrm{~m}$ \\
\hline Mode & Strip-map \\
\hline Polarisation & VV \\
\hline Type & SLC \\
\hline Acquisition date & September 22nd,2019 \\
\hline \multicolumn{2}{|c|}{ After Earthquake } \\
\hline Spatial Resolution & $1.5 \mathrm{~m}$ \\
\hline Mode & Strip-map High Resolution \\
\hline Polarisation & $\mathrm{VV}$ \\
\hline Type & SLC \\
\hline Acquisition date & November $2^{\text {nd }}, 2020$ \\
\hline
\end{tabular}

Table 2. Properties of the SAR image.

For ICEYE images (Fig.4), the strip-map mode provides a spatial resolution of $3 \mathrm{~m}$ both in range and azimuth direction by covering $30 \mathrm{~km}$ for range and $50 \mathrm{~km}$ for the azimuth. The scanned area length is approximately $600 \mathrm{~km}$.
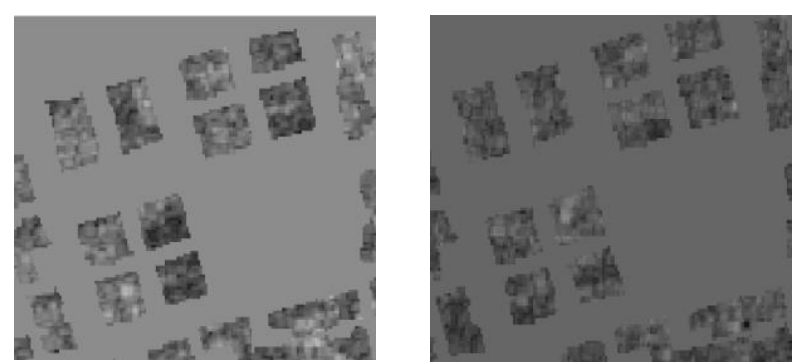

Figure 4. ICEYE SAR images with masked by building vector image (left: pre-EQ ,right: post-EQ).

The change in the majority and median values between pre and post-EQ SAR images, the collapsed buildings show same direction in two values. So, if the median values increased by the change, then the majority value shows also a increasement, and vice versa.

\subsubsection{Vector Data}

The building vector datasets which are in ESRI Shp file were provided by Here Maps to support the volunteering activities after the earthquake. We have selected a sample which includes 1255 buildings. The respective data are shown in Figure 5.

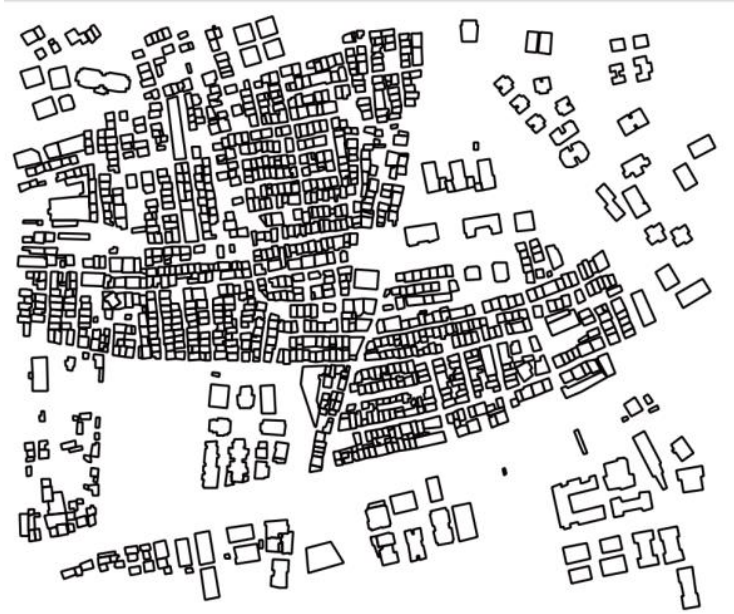

Figure 5. Building footprint vectors.

\subsection{Method}

Our method simple relies on the histogram analysis of the preand post-earthquake images with calculating simple statistics, derivation of the thresholds including the investigation of the majority of the pixels. As presented in Figure 6, the respective histogram of the red channel pixels of red rectangle significantly are different for the images of two different acquisition. But due to difficulty to analyse the histograms of the raw images, the images were first converted to principal components, then clustered with K-Means method. The statistical analysis was performed on the derived clusters for pre- and post-earthquake.

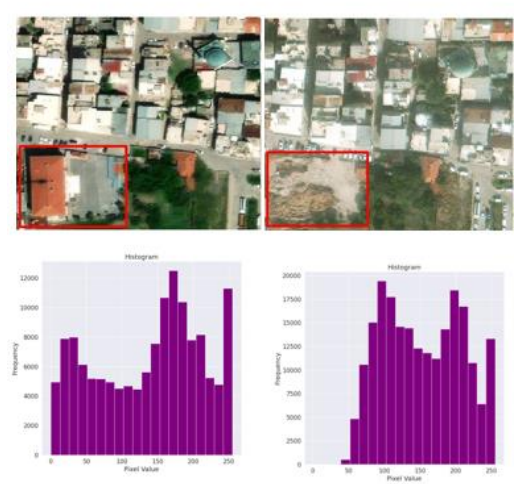

Figure 6. Pre-and after earthquake images (above), the corresponding histograms of the selected buildings (below).

The overall workflow is given in Figure 7. The methodology basically is based on the image analysis for each building vector feature. The pixels belong to each building were investigated both for optical and SAR images. Google Colab Python Notebooks was used for the whole processing including visualisation.

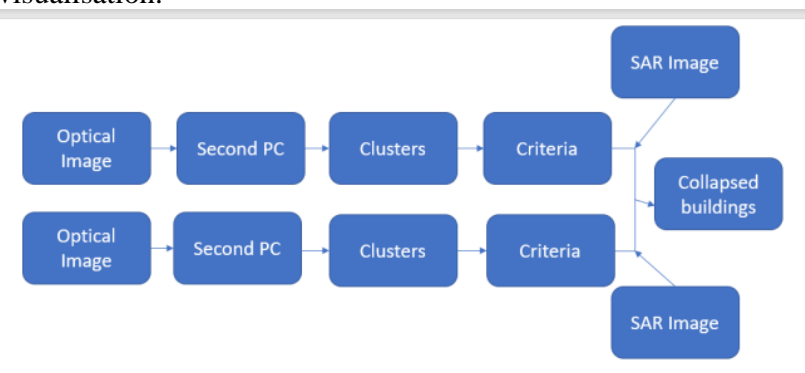

Figure 7. Method flowchart. 
Since the SAR images are with Side Looking Complex (SLC) format, they were pre-processed accordingly to project the data to the ground pixels. For this, the images were speckle filtered with Lee Filter and then SRTM DEM was used to project the datasets. The ESA SNAP Software was used for these preprocessing steps as similar applied and can be find in Köksal et al., (2021)

Then, both for optical and SAR pre-and post-earthquake images, the co-registration is applied with the use of preearthquake images as master. The principal components are useful to reduce the band information into single layers. In our approach, the second principal component is selected from four components. The pre-EQ, and the post-EQ optical imaged based second principal component images are shown in Figure 8.
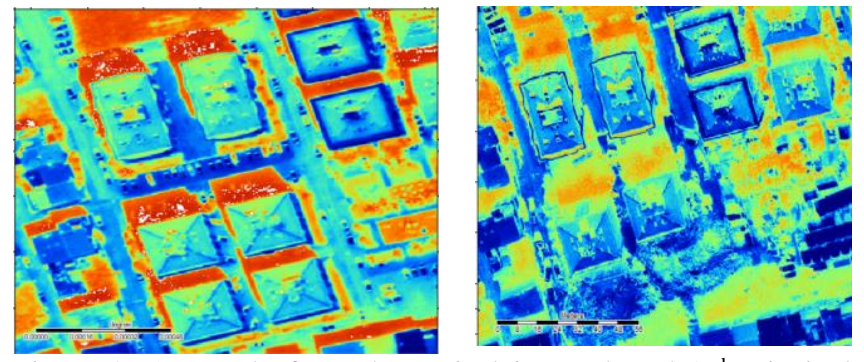

Figure 8. A sample from the optical image based $2^{\text {nd }}$ principal components (left: pre-EQ, right: post-EQ).

$\mathrm{K}$ - Means clustering was applied on the second PC both for preand post-earthquake image based principal components. The detected clusters were dramatically changed and increased among the collapsed buildings (Figure 9).
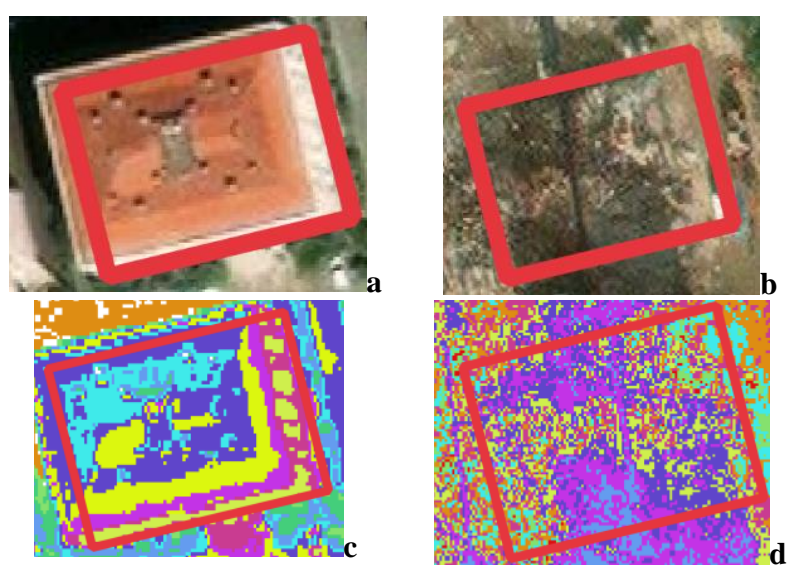

Figure 9. a-A sample building (pre-EQ), b- Collapsed (post $\mathrm{EQ})$, c-Cluster from pre-EQ, d- c-Clusters from post-EQ).

\section{RESULTS AND DISCUSSION}

In our method the main assumption, the area of the majority class of the clusters in the building areas would be changed between the historic images. Thus, the majority of the clusters were identified, their areas were calculated, and then they were compared along the values between pre- and post-earthquake dates.

SAGA GIS software package was used to apply principal component analysis and the K-means clustering.

The initial number of clusters were selected as 20 which was considered as much as high value to avoid large classes which can be separated. The calculated statistics are exported to csv file which was joined to the building vector file for further SQL selecting progress.

The standard deviation and count measures of the pre and post clusters were used. The number of clusters of post-EQ were expected more than the ones from the pre-earthquake as shown in Figure 6. This also increases the standard deviation.

The median values of the RGB channels of the major classes are calculated for each building for pre- and post- earthquake dates. The following formula is suggested to perform the analysis of the differences.

$$
S=\mid \operatorname{Rmed}_{\text {pre }}-\text { Rmed }_{\text {post }}|\cdot| \text { Gmed }_{\text {pre }}-\text { Gmed }_{\text {post }}|\cdot| \text { Bmed }_{\text {pre }} \text { Bmed }_{\text {post }} \mid \text { (1) }
$$

Where $\mathrm{R}, \mathrm{G}, \mathrm{B}$ are the image channels, $\mathrm{s}$ is the similarity measure. Same measure was also applied for the standard deviations of RGB values. The acronym 'med' refers to the median. The change in RGB values independently is also expected higher for the collapsed buildings. . Each absolute value is expected to be higher than 40 which was predefined empirically.

For the SAR images, with the assumption that the decreasing or increasing of the median scattering will be present for the majority scattering values. If the median scattering value for the building polygon increases, then we expect same behaviour also for the maximum scattering values for the pre- and post- cases. The same applies also for the decreasing.

In general, the selected criteria are shown in the following Table 3.

\begin{tabular}{|c|c|c|}
\hline Similarity measure & Source Data & Value \\
\hline$S$ (from Eq. 1) & Optical & 3500 \\
\hline $\begin{array}{l}\text { Median and } \\
\text { Majority }\end{array}$ & SAR & $\begin{array}{l}\text { Same order for } \\
\text { Pre- and Post- }\end{array}$ \\
\hline Standard Deviation & Optical & $\begin{array}{l}\text { Bigger for the } \\
\text { post- for } \\
\text { R,G,B }\end{array}$ \\
\hline $\begin{array}{l}\text { Absolute Change in } \\
\text { RGB }\end{array}$ & Optical & Bigger than 40 \\
\hline $\begin{array}{ll}\text { Clusters } & \text { from } \\
\text { Principal } & \\
\text { components } & \end{array}$ & Optical & $\begin{array}{l}\text { Standard } \\
\text { deviation is } \\
\text { bigger for the } \\
\text { post-, Rate of } \\
\text { cluster count } \\
\text { for post/pre is } \\
\text { bigger than } \\
1.7 \text {, and count } \\
\text { for post- } \\
\text { bigger than } \\
900 \text {. }\end{array}$ \\
\hline
\end{tabular}

Table 3. Criteria for detecting the collapsed buildings.

In the end, the five collapsed buildings (one has two parts, thus, there are six detected in the results) could be detected, but with 
including 12 additional wrongly detected buildings out of 1255 buildings as shown in Figure 10.

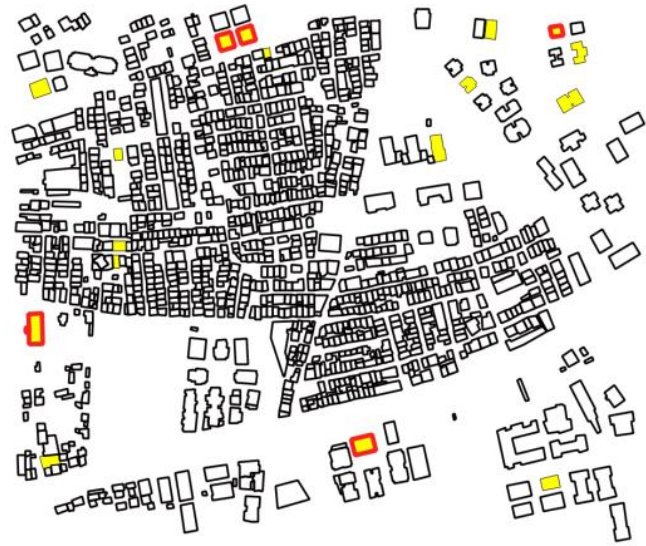

Figure 10. Detection of collapsed buildings(yellow), reds are the ground truth.

The one of the challenges is caused by the alignment of the preand post-EQ images, especially for the tall buildings. Due to viewing angle of the satellite, the tall buildings coverage looks different in both images as shown in Figure 11. This produces false positives in the results.
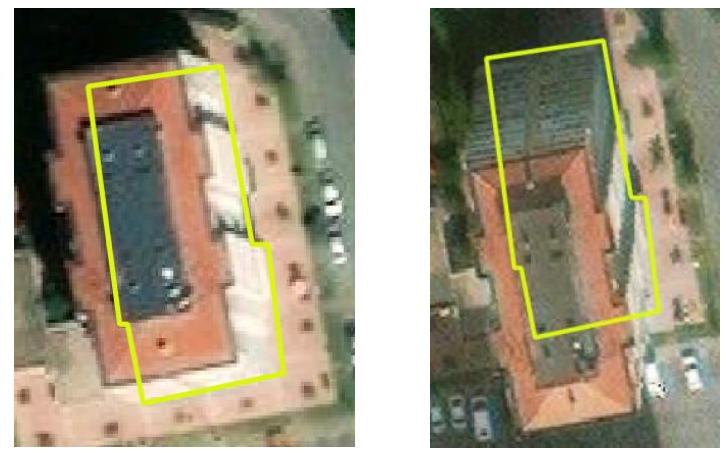

Figure 11. One example from False positive result. Yellow: Vector dataset. The building height is 42 meters.

As shown in Figure 11, the tall building has different coverage in the provided vector dataset due to its elevation. Same condition is also appeared in the case which is shown in Figure 12.
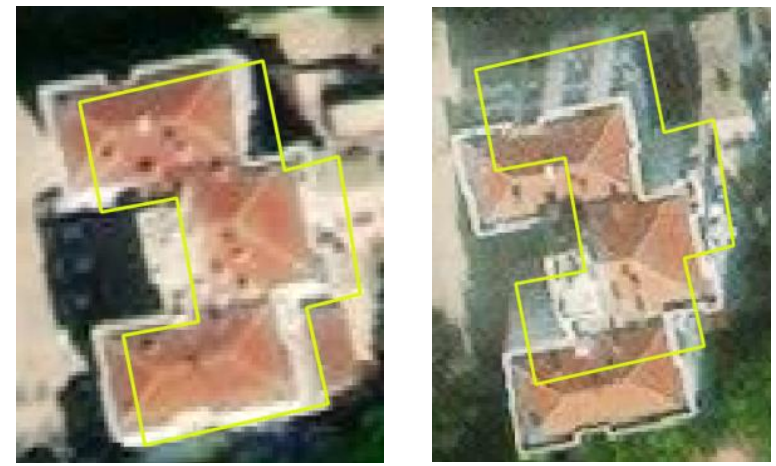

Figure 12. One example from False positive result. Yellow: Vector dataset. The building height is 24 meters.

Another case of false positive is non-building object in the vector dataset which was a basketball field in the post-EQ image. The field was a $3 \mathrm{~m}$ height building at day of the pre-EQ image as shown in Figure 13.
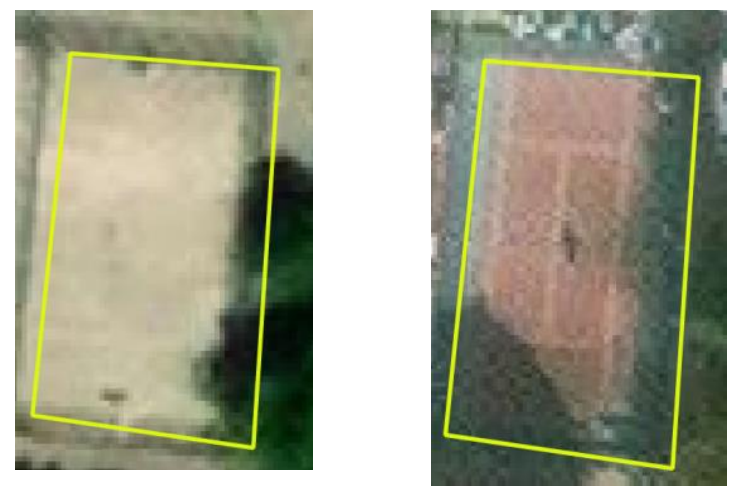

Figure 13. One example from False positive result. Yellow: Vector dataset. The building height is 3 meters.

One another problem is changing the roof structure or installation of some facilities on the roofs which were available on the post-EQ images as shown in Figure 14.
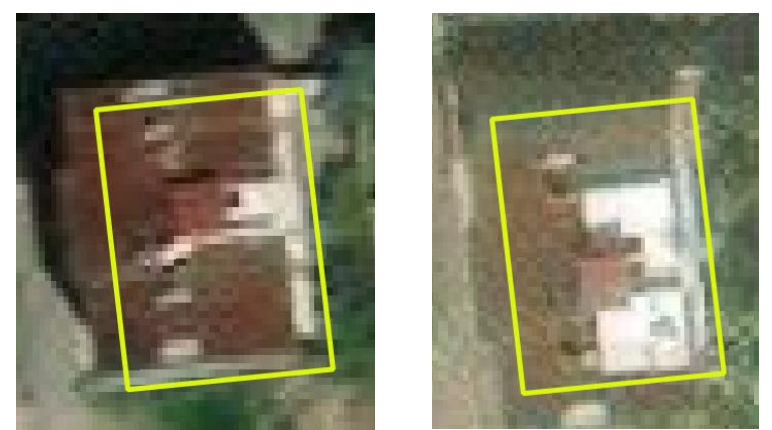

Figure 14. One example from False positive result. Yellow: Vector dataset.(Left: Pre-EQ, righ: Post-EQ

\section{CONCLUSIONS}

In this study, we have detected the collapsed buildings from with use of the optical and SAR images. The optical images were pre-processed to derive the clusters for pre- and postearthquake situation.

The principal components were used to reduce the number of bands, and unsupervised clustering provided sufficient regions to identify the building roofs. The completeness is the maximum as all collapsed buildings could be detected correctly on the test area. But there are false positive results which effect the correctness of the results. They are mainly effected by the tall buildings, other buildings which were not collapsed by the EQ, but the field use has been changed as Figure 14 . Some false positives include the buildings which have different roof structure between pre and post-EQ conditions.

The change of cluster areas on the roofs were significant for the collapsed buildings. On the other hand, in our study, the capability of SAR images was limited since different acquisition modes which were ascending, and descending were available. This makes the change detection analysis for the buildings harder. But SAR images were still used to support the results derived from the optical images.

In future studies, we will continue working on the topic to improve the derive results with the elimination of the omission errors. 


\section{ACKNOWLEDGEMENT}

This research was supported by Akdeniz University the Scientific Research Projects Coordination Unit with Project Nr. FBG-2020-5156, and European Space Agency with Project Nr. 64318. The authors also acknowledge Maxar and Here maps for the public datasets.

\section{REFERENCES}

Adriano, B., Yokoya, N., Xia, J., Miura, H., Liu, W., Matsuoka, M., Koshimura, S., 2021. Learning from multimodal and multitemporal earth observation data for building damage mapping. ISPRS J. Photogramm. Remote Sens. 175, 132-143. https://doi.org/10.1016/j.isprsjprs.2021.02.016

Azak, S., 2020. 30 Ekim 2020 İzmir-Seferihisar Açıkları (Sisam) Depremi (Mw 6.6) Keşif Gözlemleri ve Bulgular (in Turkish).

Brunner, D., Lemoine, G., Bruzzone, L., 2010. Earthquake damage assessment of buildings using VHR optical and SAR imagery. IEEE Trans. Geosci. Remote Sens. 48, 2403-2420. https://doi.org/10.1109/TGRS.2009.2038274

Chini, M., Pacifici, F., Emery, W.J., 2009. Morphological operators applied to X-band SAR for urban land use classification, in: International Geoscience and Remote Sensing Symposium https://doi.org/10.1109/IGARSS.2009.5417424 (IGARSS).

Deniz, A., Yuksel, E., Celik, O.C., Cakir, Z., Yaltirak, C., Serter, E., Yildirim, H., Gullu, A., 2020. 30.10.2020 Izmir Depremi Değerlendirme Raporu.

Dong, L., Shan, J., 2013. A comprehensive review of earthquake-induced building damage detection with remote sensing techniques. ISPRS J. Photogramm. Remote Sens. https://doi.org/10.1016/j.isprsjprs.2013.06.011

Du, Y., Gong, L., Li, Q., Wu, F., 2020. Earthquake-Induced Building Damage Assessment on SAR Multi-Texture Feature Fusion, in: International Geoscience and Remote Sensing Symposium (IGARSS). Institute of Electrical and Electronics Engineers Inc., pp. 6608-6610. https://doi.org/10.1109/IGARSS39084.2020.9323644

ElGharbawi, T., Zarzoura, F., 2021. Damage detection using SAR coherence statistical analysis, application to Beirut, Lebanon. ISPRS J. Photogramm. Remote Sens. 173, 1-9. https://doi.org/10.1016/j.isprsjprs.2021.01.001

Huyck, C.K., Adams, B.J., Cho, S., Chung, H.-C., Eguchi, R.T., 2005. Towards Rapid Citywide Damage Mapping Using Neighborhood Edge Dissimilarities in Very HighResolution Optical Satellite Imagery-Application to the 2003 Bam, Iran, Earthquake. Earthq. Spectra 21, 255266. https://doi.org/10.1193/1.2101907

Janalipour, M., Mohammadzadeh, A., 2016. Building Damage Detection Using Object-Based Image Analysis and ANFIS from High-Resolution Image (Case Study: BAM Earthquake, Iran). IEEE J. Sel. Top. Appl. Earth Obs. Remote Sens. 9, 1937-1945. https://doi.org/10.1109/JSTARS.2015.2458582

Köksal, H., Demir, N., Kilcik, A., 2021. Analysis of the Cosmic
Ray Effects on Sentinel-1 SAR Satellite Data. Aerospace 8, 62. https://doi.org/10.3390/aerospace8030062

Kutluca, A.K., 2006. The İzmir City And Natural Hazard Risks, in: ESRA Conference. pp. 1-22.

Liu, W., Yamazaki, F., 2012. Object-Based Shadow Extraction and Correction of High-Resolution Optical Satellite Images. IEEE J. Sel. Top. Appl. Earth Obs. Remote Sens. 5 , https://doi.org/10.1109/JSTARS.2012.2189558 1296-1302.

Massonnet, D., Rossi, M., Carmona, C., Adragna, F., Peltzer, G., Feigl, K., Rabaute, T., 1993. The displacement field of the Landers earthquake mapped by radar interferometry. Nature 364.

Nurlu, M., 2020. 30 Ekim 2020 Sisam Adas1 (İzmir Seferihisar Açıkları) Mw 6.6 Depremi Raporu (In Turkish).

Özmen, B., 2012. Türkiye Deprem Bölgeleri Haritalarının Tarihsel Gelişimi. Geol. Bull. Turkey 55, 43-55.

Piscini, A., Romaniello, V., Bignami, C., Stramondo, S., 2017. A New Damage Assessment Method by Means of Neural Network and Multi-Sensor Satellite Data. Appl. Sci. 7, 781. https://doi.org/10.3390/app7080781

Pulvirenti, L., Chini, M., Pierdicca, N., Boni, G., 2016. Use of SAR data for detecting floodwater in urban and agricultural areas: The role of the interferometric coherence. IEEE Trans. Geosci. Remote Sens. 54, 15321544. https://doi.org/10.1109/TGRS.2015.2482001

Sozbilir, H., Softa, M., Eski, S., Tepe, Ç., Akgun, M., Pamukçu, O.A., Çırmık, A., Utku, M., Ozdag, M., Ozden, G., Ozcelik, O., Evlek, D.A., Cakir, R., Baba, A., Uzelli, T., Tatar, O., 2020. 30 Ekim 2020 Sisam (SAMOS) Depremi (Mw: 6,9) Değerlendirme Raporu. Izmir.

Stepinac, M., Lourenço, P.B., Atalić, J., Kišiček, T., Uroš, M., Baniček, M., Šavor Novak, M., 2021. Damage classification of residential buildings in historical downtown after the ML5.5 earthquake in Zagreb, Croatia in 2020. Int. J. Disaster Risk Reduct. 56, 102140. https://doi.org/10.1016/j.ijdrr.2021.102140

Stramondo, S., Bignami, C., Chini, M., Pierdicca, N., Tertulliani, A., 2006. Satellite radar and optical remote sensing for earthquake damage detection: Results from different case studies. Int. J. Remote Sens. 27, 44334447. https://doi.org/10.1080/01431160600675895

Stramondo, S., Trasatti, E., Albano, M., Moro, M., Chini, M., Bignami, C., Polcari, M., Saroli, M., 2016. Uncovering deformation processes from surface displacements. J. Geodyn. https://doi.org/10.1016/j.jog.2016.08.001

Ünlü, R., Kiriş, R., 2021. Detection of damaged buildings after an earthquake with convolutional neural networks in conjunction with image segmentation. Vis. Comput. 110. https://doi.org/10.1007/s00371-020-02043-9

Yang, W., Zhang, X., Luo, P., 2021. Transferability of Convolutional Neural Network Models for Identifying Damaged Buildings Due to Earthquake. Remote Sens. 13, 504. https://doi.org/10.3390/rs13030504 